\title{
When is mesh fixation in TAPP-repair of primary inguinal hernia repair necessary? The register-based analysis of 11,230 cases
}

\author{
F. Mayer ${ }^{1} \cdot$ H. Niebuhr ${ }^{2} \cdot$ M. Lechner ${ }^{1}$ A. Dinnewitzer ${ }^{1} \cdot$ G. Köhler ${ }^{3}$. \\ M. Hukauf ${ }^{4} \cdot$ R. H. Fortelny ${ }^{5} \cdot$ R. Bittner $^{6}$ - F. Köckerling ${ }^{7}$
}

Received: 1 October 2015/Accepted: 11 January 2016/Published online: 17 February 2016

(c) The Author(s) 2016. This article is published with open access at Springerlink.com

\begin{abstract}
Whereas for TEP the guidelines do not recommend mesh fixation on the basis of meta-analyses regardless of the defect size, for TAPP mesh fixation can be omitted only up to a defect size of $3 \mathrm{~cm}$ because of the paucity of studies on this topic. Hence, this study now seeks to explore this subject on the basis of prospective data from the Herniamed Hernia Registry. In the period September 01, 2009, to January 31, 2014, 11,228 male patients were operated on with the TAPP technique for a primary unilateral inguinal hernia and were followed up for 1 year. Mesh fixation was used for $7422(66.1 \%)$ of these patients and no mesh fixation for 3806 patients $(33.9 \%)$. Unadjusted analysis did not find any significant difference in the recurrence rate $(0.88 \%$ with fixation vs.
\end{abstract}

F. Mayer and H. Niebuhr have contributed equally to the publication.

F. Mayer

f.mayer@salk.at

1 Department of Surgery, Paracelsus Medical University, Müllner Hauptstrasse 48, 5020 Salzburg, Austria

2 Hanse Hernia Center, Hamburg, Germany

3 Department of General and Visceral Surgery, Sisters of Charity Hospital, Linz, Austria

4 StatConsult GmbH, Magdeburg, Germany

5 Department of General, Visceral and Oncological Surgery, Wilhelminenspital, Vienna, Austria

6 Hernia Center, Winghofer Medicum, Rottenburg am Neckar, Germany

7 Department of Surgery and Center of Minimally Invasive Surgery, Academic Teaching Hospital of Charité Medical School, Vivantes Hospital Spandau, Neue Bergstrasse 6, 13585 Berlin, Germany
$1.1 \%$ without fixation; $p=0.259$ ). Multivariable analysis of all potential influence factors (age, ASA, BMI, risk factors, defect size, mesh fixation, localization of defect, mesh size) did not identify any factor that impacted recurrence on 1-year follow-up. Only for medial and combined defect localization versus lateral localization was a highly significant effect identified $(p<0.001)$. With mesh fixation and larger mesh size, it was possible to significantly reduce the recurrence rate for larger medial hernias in this series $(p=0.046)$. For TAPP repair of an inguinal hernia, mesh fixation is not necessary in a significant number of patients. Patients with a medial and combined hernia are at higher risk of recurrence. In the patient series analyzed, it was possible to significantly reduce the recurrence rate with mesh fixation and larger mesh size for medial defects.

Keywords Inguinal hernia - TAPP - Mesh fixation . Medial hernia $\cdot$ Recurrence

The longstanding standard practice for TAPP was to use mesh fixation with tackers to prevent recurrence [1]. But atraumatic mesh fixation fibrin sealants are being increasingly employed to prevent chronic pain in the wake of traumatic fixation methods [2]. Numerous studies have attested to the excellent results in terms of the recurrence rate achieved with fibrin sealants for atraumatic mesh fixation [3-6]. Comparative studies then explored, in particular for the total extraperitoneal patchplasty (TEP), whether mesh fixation could be completely dispensed with [7, 8]. In the guidelines for laparoscopic (TAPP) and endoscopic (TEP) treatment of inguinal hernia of the International Endohernia Society (IEHS), a statement with level of evidence $1 \mathrm{~B}$ pointed out that fixation and non- 
fixation of the mesh were associated with equally low recurrence rates in both TAPP and TEP [9]. However, in most studies the hernia opening was small $(<3 \mathrm{~cm})$ or not measured [9]. Therefore, the guidelines recommended that when using TAPP or TEP techniques non-fixation could be considered for types L I, II, and M I, II hernias (EHS classification) [9]. For TAPP and TEP repair of big defects (L III, M III), the mesh should be fixed [9]. In an update of the Guidelines of the International Endohernia Society, ten new studies with evidence level 1 have been included. For TEP, with evidence level $1 \mathrm{~A}$, these stated that fixation and non-fixation of the mesh in TEP were associated with an equal risk of recurrence [10]. For TAPP, the recommendations remained unchanged. Hence, in the case of TAPP it remained unclear whether mesh fixation was needed to prevent recurrence, at least for defect sizes $>3 \mathrm{~cm}$ (EHS classification L III, M III). Therefore, this paper now seeks to explore this subject on the basis of prospective data of the Herniamed Hernia Registry.

\section{Patients and methods}

As of March, 19, 2015, 426 participating hospitals and office-based surgeons mainly from Germany, Austria, and Switzerland had entered prospective data into the multicenter internet-based Herniamed Hernia Registry on their patients who had undergone hernia surgery [11]. This present study analyzed the prospective data collected for all male patients who had been operated on with an endoscopic TAPP technique for repair of a primary unilateral inguinal hernia in the period September 01, 2009, up to and including January 31, 2014. On 1-year follow-up, the general practitioner and patients were asked by questionnaire about any recurrences. Only those patients for whom 1-year follow-up results were available were included in the analysis. Other inclusion criteria included: age $>16$ years and medial/lateral/combined types of inguinal hernia based on the EHS classification [12]. In total, 11,228 patients were included in uni- and multivariate analysis for investigation of the impact of mesh fixation as well as of other potential influence factors impacting onset of a recurrence during the 1-year follow-up of TAPP operation. Details of all enrolled patients regarding the documented hernia defect size are given in Table 1 and of the fixation method in Table 2. During the observation period, 7422 patients $(66.1 \%)$ were operated on while using mesh fixation and 3806 patients $(33.9 \%)$ without mesh fixation.

All analyses were performed with the software SAS 9.2 (SAS institute Inc., Cary, NY, USA) and intentionally calculated to a full significance level of $5 \%$, i.e., they were not corrected in respect of multiple tests, and each $p$ value $\leq 0.05$ represents a significant result. Unadjusted analyses were carried out to analyze how any individual influence variable affected an outcome parameter. For categorical target (outcome) variables, Fisher's exact test was applied. For continuous target variables that followed the normal distribution, the robust $t$ test (Satterthwaite) was used.

To eliminate the effect of any confounders arising from different characteristics related to the patient or surgical technique, the results of unadjusted analysis were verified
Table 1 Distribution of defect size and fixation/non-fixation

Table 2 Distribution of defect size in the group with mesh fixation and fixation type

\begin{tabular}{|c|c|c|c|c|c|c|c|c|}
\hline & \multicolumn{6}{|c|}{ Size of defect } & \multirow{2}{*}{\multicolumn{2}{|c|}{ Total }} \\
\hline & \multicolumn{2}{|c|}{$\mathrm{I}(<1.5 \mathrm{~cm})$} & \multicolumn{2}{|c|}{ II $(1.5-3 \mathrm{~cm})$} & \multicolumn{2}{|c|}{ III $(>3 \mathrm{~cm})$} & & \\
\hline & $n$ & $\%$ & $n$ & $\%$ & $n$ & $\%$ & $n$ & $\%$ \\
\hline Mesh fixation & 852 & 56.76 & 4652 & 62.91 & 1918 & 82.25 & 7422 & 66.10 \\
\hline No mesh fixation & 649 & 43.24 & 2743 & 37.09 & 414 & 17.75 & 3806 & 33.90 \\
\hline Total & 1501 & 100.00 & 7395 & 100.00 & 2332 & 100.00 & 11,228 & 100.00 \\
\hline
\end{tabular}

\begin{tabular}{|c|c|c|c|c|c|c|c|c|}
\hline & \multicolumn{6}{|c|}{ Size of defect } & \multirow{2}{*}{\multicolumn{2}{|c|}{ Total }} \\
\hline & \multicolumn{2}{|c|}{$\mathrm{I}(<1.5 \mathrm{~cm})$} & \multicolumn{2}{|c|}{ II $(1.5-3 \mathrm{~cm})$} & \multicolumn{2}{|c|}{ III $(>3 \mathrm{~cm})$} & & \\
\hline & $n$ & $\%$ & $n$ & $\%$ & $n$ & $\%$ & $n$ & $\%$ \\
\hline \multicolumn{9}{|l|}{ Type of fixation } \\
\hline Suture & 121 & 14.20 & 760 & 16.34 & 446 & 23.25 & 1327 & 17.88 \\
\hline Tacker & 393 & 46.13 & 2219 & 47.70 & 956 & 49.84 & 3568 & 48.07 \\
\hline Glue & 331 & 38.85 & 1607 & 34.54 & 468 & 24.40 & 2406 & 32.42 \\
\hline Combination & 7 & 0.82 & 66 & 1.42 & 48 & 2.50 & 121 & 1.63 \\
\hline Total & 852 & 100.00 & 4652 & 100.00 & 1918 & 100.00 & 7422 & 100.00 \\
\hline
\end{tabular}


once again in multivariable analysis. In addition to fixation (yes/no), it was also possible to simultaneously review all the other influence factors.

The binary regression model for dichotomous target variables was used to identify the influence of the various factors in multivariable analysis. Odds ratios (OR) and corresponding $95 \%$ confidence intervals based on the Wald test are given for estimates. For influence variables with more than two categories, one of these values was used in each case as a reference category. For the continuous variable age (years), the 10 -year odds ratio is given, for BMI $\left(\mathrm{kg} / \mathrm{m}^{2}\right)$ a five-point odds ratio, and for mesh size the ten-point odds ratio. The results are sorted on the basis of influence and presented in tabular form.

\section{Results}

\section{Unadjusted results}

Unadjusted analysis of the groups compared, i.e., TAPP with versus without mesh fixation, revealed, in some cases, significant differences in the patient characteristics and hernia findings (Table 3). The patients in the mesh fixation group were significantly older ( 57.4 years \pm 14.8 vs. 54.4 years \pm 15.7 [mean $\pm \mathrm{STD}$ ], $p<0.001)$, and larger meshes were used $\left(151.1 \mathrm{~cm}^{2} \pm 19.3\right.$ vs. $145.8 \mathrm{~cm}^{2} \pm 15.6$ [mean \pm STD], $p<0.001)$. For large hernia defects (EHS III), the mesh was fixed significantly more often $(82.2 \%$ with mesh fixation vs. $17.8 \%$ without mesh fixation) (Table 1). Likewise, for a medial hernia the implanted mesh was fixed significantly more often (30.8\% with mesh fixation vs. $24.9 \%$ without mesh fixation; $p<0.001$ ) (Table 3). A clear difference was identified between the two groups with regard to the presence of at least one risk factor $(p=0.011)$. A large proportion, at $25.8 \%$, of patients without mesh fixation had at least one relevant risk factor compared with those without mesh fixation, at $23.6 \%(p=0.001)$. That was also true for nicotine abuse (12.4\% without mesh fixation vs. $8.7 \%$ with mesh fixation; $p<0.001)$.

Unadjusted analysis of the relationship between mesh fixation and non-fixation for TAPP did not reveal any significant difference in the recurrence rate on 1-year follow-up (Table 4). The recurrence rate was $0.9 \%$ in the mesh fixation group and $1.1 \%$ in the non-fixation group $(p=0.259)$.

\section{Multivariable analysis}

In this multivariable analysis (Table 5), all potential influence factors were reviewed with regard to onset of a recurrence. No relevant influence was identified for mesh fixation compared with non-fixation $(p=0.399)$. That was also true for the defect size ( $p=0.383)$, with no significant difference observed on comparing defect sizes $>3 \mathrm{~cm}$ (EHS classification III) with sizes $<1.5 \mathrm{~cm}$ (EHS classification I) and $1.5-3 \mathrm{~cm}$ (EHS classification II). Nor did the mesh size have any significant impact on onset of recurrence. For the patient-related influence factors such as age, ASA score, BMI value, the risk factors COPD, and smoking as well as the other risk factors, multivariable analysis did not identify any effect on onset of recurrence. The only factor that had a highly significant impact on recurrence was hernia localization $(p<0.001)$. Whereas a lateral hernia was associated with a lower probability of onset of recurrence, a medial inguinal hernia and a combined hernia with a medial portion presented a highly significantly higher risk for onset of recurrence $(p<0.001)$. With a prevalence of $0.9 \%$ for the entire patient collective, this would correspond to five recurrences for every 1000 operations of hernias with lateral EHS localization compared with 11 recurrences for patients with medial EHS localization. Hence, medial and combined hernias constitute a highly significant risk factor for onset of recurrence following TAPP, but that was not true for patient-related factors, hernia size, and mesh non-fixation.

\section{Subgroup analysis}

If, in view of the results of multivariable analysis, one compares the recurrence rates in unadjusted analysis in relation to the EHS localization, highly significant differences unfavorable to medial and combined hernias are seen (Table 6). If one then checks the role of fixation in the medial inguinal hernia group, which is at higher risk of recurrence, one notes that it was possible to significantly reduce the recurrence rate with mesh fixation (Table 7). No significant difference was found in the recurrence rate between the various fixation techniques (tacker, glue, suture, combination) (Table 8). In addition, where mesh fixation was used to repair medial inguinal hernias, a significantly larger mesh size was used (Table 9). Besides, analysis of the meshes used for at least $5 \%$ of medial inguinal hernias demonstrated significant differences (Table 10). For example, one notable finding was that in the group with no mesh fixation a greater number of selfadhesive, titanized, and 3D standard meshes were used (Table 10). Since the medial sac reduction is not documented in the Herniamed Registry, no conclusions on its implications can be drawn from the data presented here.

\section{Discussion}

This present analysis of data from the Herniamed Hernia Registry compared the recurrence rates on 1-year followup in respect of mesh fixation versus non-fixation in TAPP. 
Table 3 Demographic and surgery-related data

\begin{tabular}{|c|c|c|c|c|c|}
\hline & & Mesh fixation & & No mesh fixation & $p$ \\
\hline Age (years) & Mean \pm STD & $57.4 \pm 14.8$ & & $54.4 \pm 15.7$ & $<0.001$ \\
\hline BMI $\left(\mathrm{kg} / \mathrm{m}^{2}\right)$ & Mean \pm STD & $25.9 \pm 3.4$ & & $25.9 \pm 3.3$ & 0.573 \\
\hline \multirow[t]{2}{*}{ Mesh size $\left(\mathrm{cm}^{2}\right)$} & Mean \pm STD & $151.1 \pm 19.3$ & & $145.8 \pm 15.6$ & $<0.001$ \\
\hline & $n(7422)$ & $\%$ & $n(3806)$ & $\%$ & $p$ \\
\hline \multicolumn{6}{|l|}{ ASA } \\
\hline I & 2601 & 35.04 & 1282 & 33.68 & 0.027 \\
\hline II & 3994 & 53.81 & 2037 & 53.52 & \\
\hline III/IV & 827 & 11.14 & 487 & 12.80 & \\
\hline \multicolumn{6}{|l|}{ Defect size (EHS) } \\
\hline $\mathrm{I}(<1.5 \mathrm{~cm})$ & 852 & 11.48 & 649 & 17.05 & $<0.001$ \\
\hline II $(1.5-3 \mathrm{~cm})$ & 4652 & 62.68 & 2743 & 72.07 & \\
\hline III $(>3 \mathrm{~cm})$ & 1918 & 25.84 & 414 & 10.88 & \\
\hline \multicolumn{6}{|c|}{ Localization of defect (EHS) } \\
\hline Medial (M) & 2285 & 30.79 & 948 & 24.91 & $<0.001$ \\
\hline Lateral (L) & 4477 & 60.32 & 2298 & 60.38 & \\
\hline Combined (C) & 660 & 8.89 & 560 & 14.71 & \\
\hline \multicolumn{6}{|l|}{ Risk factors } \\
\hline \multicolumn{6}{|l|}{ Overall } \\
\hline Yes & 1749 & 23.57 & 980 & 25.75 & 0.011 \\
\hline No & 5673 & 76.43 & 2826 & 74.25 & \\
\hline \multicolumn{6}{|l|}{ COPD } \\
\hline Yes & 321 & 4.32 & 196 & 5.15 & 0.051 \\
\hline No & 7101 & 95.68 & 3610 & 94.85 & \\
\hline \multicolumn{6}{|l|}{ Diabetes } \\
\hline Yes & 318 & 4.28 & 164 & 4.31 & 0.961 \\
\hline No & 7104 & 95.72 & 3642 & 95.69 & \\
\hline \multicolumn{6}{|l|}{ Aortic aneurysm } \\
\hline Yes & 22 & 0.30 & 9 & 0.24 & 0.705 \\
\hline No & 7400 & 99.70 & 3797 & 99.76 & \\
\hline \multicolumn{6}{|c|}{ Immunosuppression } \\
\hline Yes & 34 & 0.46 & 14 & 0.37 & 0.544 \\
\hline No & 7388 & 99.54 & 3792 & 99.63 & \\
\hline \multicolumn{6}{|l|}{ Corticoids } \\
\hline Yes & 50 & 0.67 & 23 & 0.60 & 0.711 \\
\hline No & 7372 & 99.33 & 3783 & 99.40 & \\
\hline \multicolumn{6}{|l|}{ Smoking } \\
\hline Yes & 643 & 8.66 & 470 & 12.35 & $<.001$ \\
\hline No & 6779 & 91.34 & 3336 & 87.65 & \\
\hline \multicolumn{6}{|l|}{ Coagulopathy } \\
\hline Yes & 74 & 1.00 & 37 & 0.97 & 1.000 \\
\hline No & 7348 & 99.00 & 3769 & 99.03 & \\
\hline \multicolumn{6}{|c|}{ Antiplatelet medication } \\
\hline Yes & 525 & 7.07 & 206 & 5.41 & $<0.001$ \\
\hline No & 6897 & 92.93 & 3600 & 94.59 & \\
\hline \multicolumn{6}{|c|}{ Cumarin medication } \\
\hline Yes & 133 & 1.79 & 52 & 1.37 & 0.100 \\
\hline No & 7289 & 98.21 & 3754 & 98.63 & \\
\hline
\end{tabular}

Demographic parameters (Table 3) are demonstrated in relation to fixation/non-fixation and include the age of the patients (years), BMI $\left(\mathrm{kg} / \mathrm{m}^{2}\right)$, size of the mesh implant $\left(\mathrm{cm}^{2}\right)$, ASA score (I-IV), size of the hernia defect (EHS I-III), localization of the hernia defect (medial-M/lateral-L/combined-C; EHS classification), and hernia-specific risk factors 
Table 4 Unadjusted analysis of the recurrence rates on 1-year follow-up

\begin{tabular}{|c|c|c|c|c|c|}
\hline & \multicolumn{2}{|c|}{ Mesh fixation } & \multicolumn{2}{|c|}{ No mesh fixation } & \multirow[t]{2}{*}{$p$} \\
\hline & $n$ & $\%$ & $n$ & $\%$ & \\
\hline \multicolumn{6}{|c|}{ Recurrent hernia (1-year follow-up: $100 \%$ ) } \\
\hline Yes & 65 & 0.88 & 42 & 1.10 & 0.259 \\
\hline No & 7357 & 99.12 & 3764 & 98.90 & \\
\hline
\end{tabular}

Univariable analysis did not find any significant difference between these two parameters. However, since there were significant differences between the two groups in terms of their demographic and surgery-related data, multivariable analysis was performed to identify the influence factors that significantly impacted the recurrence rate on 1-year follow-up. The latter revealed that for TAPP, too, mesh fixation did not have any relevant impact on the recurrence rate regardless of the defect size. A similar conclusion was reported by a prospective randomized trial that compared 273 TAPP operations with mesh fixation versus 263 without mesh fixation [13].

Nor did multivariable analysis find any evidence that age, ASA score, BMI value, or patient-related risk factors exerted any influence on onset of recurrence. Here it must be pointed out that unlike one systematic review [14], no effect on recurrence rate was identified for patients with either COPD or nicotine abuse.

The only highly significant factor impacting onset of recurrence following TAPP for primary unilateral inguinal hernia repair in men was a medial or combined hernia based on the EHS classification. That finding was also confirmed in the systematic review by Burcharth et al. [14] which found that a direct inguinal hernia was found to be a
Table 6 Comparision of recurrence rates depending on EHS localization

\begin{tabular}{|c|c|c|c|c|c|c|c|}
\hline & \multicolumn{2}{|c|}{ Medial } & \multicolumn{2}{|c|}{ Lateral } & \multicolumn{2}{|c|}{ Combined } & \multirow[t]{2}{*}{$p$} \\
\hline & $n$ & $\%$ & $n$ & $\%$ & $n$ & $\%$ & \\
\hline \multicolumn{8}{|c|}{ Recurrence } \\
\hline Yes & 44 & 1.36 & 44 & 0.65 & 19 & 1.56 & $<0.001$ \\
\hline No & 3190 & 98.64 & 6732 & 99.35 & 1201 & 1.56 & \\
\hline
\end{tabular}

Table 7 Comparision of recurrence rates in TAPP with and without mesh fixation in medial inguinal hernias

\begin{tabular}{lrrrrrr}
\hline & \multicolumn{2}{l}{ Mesh fixation } & & \multicolumn{2}{l}{ No mesh fixation } & $p$ \\
\cline { 2 - 3 } & $n$ & $\%$ & & $n$ & $\%$ & \\
\hline Recurrence & & & & & \\
Yes & 25 & 1.09 & & 19 & 2.00 & 0.046 \\
No & 2260 & 98.91 & & 929 & 98.00 & \\
\hline
\end{tabular}

risk factor for recurrence with a pooled RR of $1.91(95 \%$ CI 1.62-2.36; $p<0.001$ ).

Unlike a lateral inguinal hernia, where the peritoneal hernia sac is removed from the inguinal canal and the inguinal canal closes curtain-like, additional surgical measures are necessary taken to repair the hernia defect for the medial inguinal hernia $[9,15-19]$. The content of the direct hernia cavity, generally composed of preperitoneal fat, is dissected out, leaving the hernia cavity as a rigid outpouching of the transversalis fascia. Consequently, there is a higher risk of seroma for medial inguinal hernias following endoscopic repair [9, 15-19]. This medial hernia cavity is at also greater risk of recurrence since it represents more a bridging situation compared with the lateral inguinal hernia. Therefore, the requirements for adequate overlap are more stringent.
Table 5 Multivariable analysis of recurrence (model fit: $p=0.004)$

\begin{tabular}{lclccc}
\hline Parameter & $p$ value & Variables & OR & 95 \%-CI \\
\hline Localization of defect (EHS) & $<0.001$ & Combined versus medial & 1.137 & 0.656 & 1.970 \\
& & Lateral versus medial & 0.463 & 0.303 & 0.707 \\
Risk factors: COPD/smoking & 0.097 & Yes versus no & 0.556 & 0.278 & 1.111 \\
BMI (five-point OR) & 0.109 & & 1.240 & 0.953 & 1.613 \\
Size of mesh (ten-point OR) & 0.192 & & 0.929 & 0.832 & 1.038 \\
Size of defect (EHS) & 0.383 & I $(<1.5 \mathrm{~cm})$ versus III $(>3 \mathrm{~cm})$ & 1.330 & 0.694 & 2.546 \\
& & II $(1.5-3 \mathrm{~cm})$ versus III $(>3 \mathrm{~cm})$ & 0.914 & 0.558 & 1.499 \\
Fixation of mesh & 0.399 & No fixation versus fixation & 1.194 & 0.791 & 1.800 \\
Risk factors (others) & 0.408 & Yes versus no & 1.269 & 0.721 & 2.234 \\
ASA & 0.720 & II versus I & 1.106 & 0.683 & 1.791 \\
& & III/IV versus I & 1.352 & 0.650 & 2.812 \\
Age [10-year OR] & 0.869 & & 1.013 & 0.868 & 1.183 \\
\hline
\end{tabular}

${ }^{a}$ Risk factors (others): immunosuppression, antiplatelet medication, coagulopathy, diabetes, corticoids, anticoagulation, aortic aneurysm 
Table 8 Comparision of recurrence rates in TAPP with mesh fixation depending on type of fixation in medial inguinal hernias

\begin{tabular}{|c|c|c|c|c|c|c|c|c|}
\hline \multicolumn{2}{|c|}{ Suture } & \multicolumn{2}{|c|}{ Tacker } & \multicolumn{2}{|c|}{ Glue } & \multicolumn{2}{|c|}{ Combined } & $p$ \\
\hline$n$ & $\%$ & $n$ & $\%$ & $n$ & $\%$ & $n$ & $\%$ & \\
\hline
\end{tabular}

\begin{tabular}{|c|c|c|c|c|c|c|c|c|c|}
\hline \multicolumn{10}{|c|}{ Recurrence } \\
\hline Yes & 4 & 0.97 & 16 & 1.34 & 5 & 0.79 & 0 & 0 & 0.746 \\
\hline No & 407 & 99.03 & 1182 & 98.66 & 627 & 99.21 & 44 & 100.00 & \\
\hline
\end{tabular}

Table 9 Comparision of mesh sizes in TAPP with and without mesh fixation in medial inguinal hernias

\begin{tabular}{|c|c|c|c|c|}
\hline & & \multicolumn{2}{|l|}{ Fixation } & \multirow[t]{2}{*}{$p$} \\
\hline & & Mesh fixation $(n=2285)$ & No Mesh fixation $(n=948)$ & \\
\hline Mesh size $\left(\mathrm{cm}^{2}\right)$ & Mean \pm STD & $151.0 \pm 21.1$ & $145.2 \pm 19.0$ & $<0.001$ \\
\hline
\end{tabular}

Table 10 Comparision of meshes used in TAPP with and without mesh fixation in medial inguinal hernias

\begin{tabular}{|c|c|c|c|c|c|}
\hline & \multicolumn{2}{|c|}{ Mesh fixation } & \multicolumn{2}{|c|}{ No mesh fixation } & \multirow[t]{2}{*}{$p$} \\
\hline & $n$ & $\%$ & $n$ & $\%$ & \\
\hline \multicolumn{6}{|l|}{ Type of meshes } \\
\hline Other $<5 \%$ & 1079 & 47.22 & 416 & 43.88 & $<0.001$ \\
\hline Ultrapro & 604 & 26.43 & 80 & 8.44 & \\
\hline Parietene ProGrip & 6 & 0.26 & 186 & 19.62 & \\
\hline TiMesh light & 184 & 8.05 & 107 & 11.29 & \\
\hline 3DMax Light Mesh & 61 & 2.67 & 135 & 14.24 & \\
\hline Optilene Mesh LP & 351 & 15.36 & 24 & 2.53 & \\
\hline
\end{tabular}

It is crucial when using an endoscopic technique (TEP, TAPP) to repair medial inguinal hernia that "complete medial sac reduction" be performed to avoid onset of seroma or recurrence. Since the lining of the medial hernia cavity is formed by the transversalis fascia outpouching, the latter is clasped and pulled inwards until the space is completely reduced ("complete medial sac reduction") $[9$, 15-19]. Next, the transversalis fascia that has been pulled inwards is now either fixed with a suture to Cooper's ligament or blocked off with a Roeder loop $[18,19]$. The utmost attention should be paid to this technical step of "complete medial sac reduction" in both TAPP and TEP since it serves to prevent seromas as well as recurrence.

Moreover, in this situation it may be necessary to use a mesh size of $17 \times 12 \mathrm{~cm}$ instead of the standard size of $15 \times 10 \mathrm{~cm}$. For example, analysis of the subgroup of medial inguinal hernias in the Herniamed Registry did indeed reveal that in the mesh fixation group significantly larger size meshes were used. By contrast, in the group with no mesh fixation a greater number of self-adhesive, titanized and 3D standard meshes were also used. The data presented here also demonstrate that for larger medial and combined hernias additional fixation of the mesh is needed using either properly placed absorbable tackers, sutures, or atraumatic fibrin sealants. The data also show that the type of fixation did not impact the recurrence rate.
In summary, it can be stated that for TAPP repair of an inguinal hernia fixation of the mesh is not needed in a significant number of patients. Patients with a medial and combined hernia are at a higher risk of recurrence. The choice of a greater mesh and "complete medial sac reduction" must be carefully made to obtain a plane inguinal region surface for mesh placement and greater mesh overlap. This helps to reduce both the recurrence and the seroma rates. The present study has demonstrated that on using mesh fixation for TAPP, regardless of whether with tacker, suture, glue, or combined, the recurrence rates for larger medial hernias were significantly lower.

Acknowledgments Open access funding provided by Paracelsus Medical University. Ferdinand Köckerling-Grants to fund the Herniamed Registry from Johnson \& Johnson, Norderstedt, Karl Storz, Tuttlingen, pfm medical, Cologne, Dahlhausen, Cologne, B Braun, Tuttlingen, MenkeMed, Munich and Bard, Karlsruhe.

Disclosures F. Mayer, H. Niebuhr, M. Lechner, A. Dinnewitzer, G. Köhler, M. Hukauf, R. H. Fortelny, R. Bittner have no conflicts of interest or financial ties to disclose.

Open Access This article is distributed under the terms of the Creative Commons Attribution 4.0 International License (http://crea tivecommons.org/licenses/by/4.0/), which permits unrestricted use, distribution, and reproduction in any medium, provided you give appropriate credit to the original author(s) and the source, provide a link to the Creative Commons license, and indicate if changes were made.

\section{Appendix: Herniamed Study Group}

\section{Scientific Board}

Köckerling, Ferdinand (Chairman) (Berlin); Berger, Dieter (Baden-Baden); Bittner, Reinhard (Rottenburg); Bruns, Christiane (Magdeburg); Dalicho, Stephan (Magdeburg); Fortelny, René (Wien); Jacob, Dietmar (Berlin); Koch, Andreas (Cottbus); Kraft, Barbara (Stuttgart); Kuthe, Andreas (Hannover); Lippert, Hans (Magdeburg): Lorenz, Ralph (Berlin); Mayer, Franz 
(Salzburg); Moesta, Kurt Thomas (Hannover); Niebuhr, Henning (Hamburg); Peiper, Christian (Hamm); Pross, Matthias (Berlin); Reinpold, Wolfgang (Hamburg); Simon, Thomas (Sinsheim); Stechemesser, Bernd (Köln); Unger, Solveig (Chemnitz).

\section{Participants}

Ahmetov, Azat (Saint-Petersburg); Alapatt, Terence Francis (Frankfurt/Main); Anders, Stefan (Berlin); Anderson, Jürina (Würzburg); Arndt, Anatoli (Elmshorn); Asperger, Walter (Halle); Avram, Iulian (Saarbrücken); Barkus; Jörg (Velbert); Becker, Matthias (Freital); Behrend, Matthias (Deggendorf); Beuleke, Andrea (Burgwedel); Berger, Dieter (Baden-Baden); Bittner, Reinhard (Rottenburg); Blaha, Pavel (Zwiesel); Blumberg, Claus (Lübeck); Böckmann, Ulrich (Papenburg); Böhle, Arnd Steffen (Bremen); Böttger, Thomas Carsten (Fürth); Bolle, Ludger (Berlin); Borchert, Erika (Grevenbroich); Born, Henry (Leipzig); Brabender, Jan (Köln); Brauckmann, Markus (Rüdesheim am Rhein); Breitenbuch von, Philipp (Radebeul); Brüggemann, Armin (Kassel); Brütting, Alfred (Erlangen); Budzier, Eckhard (Meldorf); Burchett, Bert (Waren); Burghardt, Jens (Rüdersdorf); Carus, Thomas (Bremen); Cejnar, Stephan-Alexander (München); Chirikov, Ruslan (Dorsten); Comman, Andreas (Bogen); Crescenti, Fabio (Verden/Aller); Dapunt, Emanuela (Bruneck); Decker, Georg (Berlin); Demmel, Michael (Arnsberg); Descloux, Alexandre (Baden); Deusch, Klaus-Peter (Wiesbaden); Dick, Marcus (Neumünster); Dieterich, Klaus (Ditzingen); Dietz, Harald (Landshut); Dittmann, Michael (Northeim); Dornbusch, Jan (Herzberg/Elster); Drummer, Bernhard (Forchheim); Eckermann, Oliver (Luckenwalde); Eckhoff, Jörn/Hamburg); Elger, Karlheinz (Germersheim); Engelhardt, Thomas (Erfurt); Erichsen, Axel (Friedrichshafen); Eucker, Dietmar (Bruderholz); Fackeldey, Volker (Kitzingen); Farke, Stefan (Delmenhorst); Faust, Hendrik (Emden); Federmann, Georg (Seehausen); Feichter, Albert (Wien); Fiedler, Michael (Eisenberg); Fischer, Ines (Wiener Neustadt); Fortelny, René H. (Wien); Franczak, Andreas (Wien); Franke, Claus (Düsseldorf); Frankenberg von, Moritz (Salem); Frehner, Wolfgang (Ottobeuren); Friedhoff, Klaus (Andernach); Friedrich, Jürgen (Essen); Frings, Wolfram (Bonn); Fritsche, Ralf (Darmstadt); Frommhold, Klaus (Coesfeld); Frunder, Albrecht (Tübingen); Fuhrer, Günther (Reutlingen); Gassler, Harald (Villach); Gawad, Karim A. Frankfurt/Main); Gerdes, Martin (Ostercappeln); Germanov, German (Halberstadt; Gilg, Kai-Uwe (Hartmannsdorf); Glaubitz, Martin (Neumünster); Glutig, Holger (Meissen); Gmeiner, Dietmar (Bad Dürrnberg); Göring, Herbert (München); Grebe, Werner (Rheda-Wiedenbrück); Grothe, Dirk (Melle);
Gürtler, Thomas (Zürich); Hache, Helmer (Löbau); Hämmerle, Alexander (Bad Pyrmont); Haffner, Eugen (Hamm); Hain, Hans-Jürgen (Gross-Umstadt); Hammans, Sebastian (Lingen); Hampe, Carsten (Garbsen); Harrer, Petra (Starnberg); Heinzmann, Bernd (Magdeburg); Heise, Joachim Wilfried (Stolberg); Heitland, Tim (München); Helbling, Christian (Rapperswil); Hempen, Hans-Günther (Cloppenburg); Henneking, Klaus-Wilhelm (Bayreuth); Hennes, Norbert (Duisburg); Hermes, Wolfgang (Weyhe); Herrgesell, Holger (Berlin); Herzing, Holger Höchstadt); Hessler, Christian (Bingen); Hildebrand, Christiaan (Langenfeld); Höferlin, Andreas (Mainz); Hoffmann, Henry (Basel); Hoffmann, Michael (Kassel); Hofmann, Eva M. (Frankfurt/Main); Hopfer, Frank (Eggenfelden); Hornung, Frederic (Wolfratshausen); Hügel, Omar (Hannover); Hüttemann, Martin (Oberhausen); Huhn, Ulla (Berlin); Hunkeler, Rolf (Zürich); Imdahl, Andreas (Heidenheim); Jacob, Dietmar (Berlin); Jenert, Burghard (Lichtenstein); Jugenheimer, Michael (Herrenberg); Junger, Marc (München); Kaaden, Stephan (Neustadt am Rübenberge); Käs, Stephan (Weiden); Kahraman, Orhan (Hamburg); Kaiser, Christian (Westerstede); Kaiser, Stefan (Kleinmachnow); Kapischke, Matthias (Hamburg); Karch, Matthias (Eichstätt); Kasparek, Michael S. (München); Keck, Heinrich (Wolfenbüttel); Keller, Hans W. (Bonn); Kienzle, Ulrich (Karlsruhe); Kipfmüller, Brigitte (Köthen); Kirsch, Ulrike (Oranienburg); Klammer, Frank (Ahlen); Klatt, Richard (Hagen); Kleemann, Nils (Perleberg); Klein, Karl-Hermann (Burbach); Kleist, Sven (Berlin); Klobusicky, Pavol (Bad Kissingen); Kneifel, Thomas (Datteln); Knoop, Michael (Frankfurt/Oder); Knotter, Bianca (Mannheim); Koch, Andreas (Cottbus); Köckerling, Ferdinand (Berlin); Köhler, Gernot (Linz); König, Oliver (Buchholz); Kornblum, Hans (Tübingen); Krämer, Dirk (Bad Zwischenahn); Kraft, Barbara (Stuttgart); Kreissl, Peter (Ebersberg); Krones, Carsten Johannes (Aachen); Kruse, Christinan (Aschaffenburg); Kube, Rainer (Cottbus); Kühlberg, Thomas (Berlin); Kuhn, Roger (Gifhorn); Kusch, Eduard (Gütersloh); Kuthe, Andreas (Hannover); Ladberg, Ralf (Bremen); Ladra, Jürgen (Düren); LahrEigen, Rolf (Potsdam); Lainka, Martin (Wattenscheid); Lammers, Bernhard J. (Neuss); Lancee, Steffen (Alsfeld); Lange, Claas (Berlin); Laps, Rainer (Ehringshausen); Larusson, Hannes Jon (Pinneberg); Lauschke, Holger (Duisburg); Leher, Markus (Schärding); Leidl, Stefan (Waidhofen/Ybbs); Lenz, Stefan (Berlin); Lesch, Alexander (Kamp-Lintfort); Liedke, Marc Olaf (Heide); Lienert, Mark (Duisburg); Limberger, Andreas (Schrobenhausen); Limmer, Stefan (Würzburg); Locher, Martin (Kiel); Loghmanieh, Siawasch (Viersen); Lorenz, Ralph (Berlin); Mallmann, Bernhard (Krefeld); Manger, Regina (Schwabmünchen); Maurer, Stephan (Münster); Mayer, Franz 
(Salzburg); Mellert, Joachim (Höxter); Menzel, Ingo (Weimar); Meurer, Kirsten (Bochum); Meyer, Moritz (Ahaus); Mirow, Lutz (Kirchberg); Mittenzwey, HansJoachim (Berlin); Mörder-Köttgen, Anja (Freiburg); Moesta, Kurt Thomas (Hannover); Moldenhauer, Ingolf (Braunschweig); Morkramer, Rolf (Xanten); Mosa, Tawfik (Merseburg); Müller, Hannes (Schlanders); Münzberg, Gregor (Berlin); Mussack, Thomas (St. Gallen); Neumann, Jürgen (Haan); Neumeuer, Kai (Paderborn); Niebuhr, Henning (Hamburg); Nix, Carsten (Walsrode); Nölling, Anke (Burbach); Nostitz, Friedrich Zoltán (Mühlhausen); Obermaier, Straubing); Öz-Schmidt, Meryem (Hanau); Oldorf, Peter (Usingen); Olivieri, Manuel (Pforzheim); Pawelzik, Marek (Hamburg); Peiper, Christian (Hamm); Peitgen, Klaus (Bottrop); Pertl, Alexander (Spittal/Drau); Philipp, Mark (Rostock); Pickart, Lutz (Bad Langensalza); Pizzera, Christian (Graz); Pöllath, Martin (Sulzbach-Rosenberg); Possin, Ulrich (Laatzen); Prenzel, Klaus (Bad Neuenahr-Ahrweiler); Pröve, Florian (Goslar); Pronnet, Thomas (Fürstenfeldbruck); Pross, Matthias (Berlin); Puff, Johannes (Dinkelsbühl); Rabl, Anton (Passau); Rapp, Martin (Neunkirchen); Reck, Thomas (Püttlingen); Reinpold, Wolfgang (Hamburg); Reuter, Christoph (Quakenbrück); Richter, Jörg (Winnenden); Riemann, Kerstin (AlzenauWasserlos); Rodehorst, Anette (Otterndorf); Roehr, Thomas (Rödental); Roncossek, Bremerhaven); Roth Hartmut (Nürnberg); Sardoschau, Nihad (Saarbrücken); Sauer, Gottfried (Rüsselsheim); Sauer, Jörg (Arnsberg); Seekamp, Axel (Freiburg); Seelig, Matthias (Bad Soden); Seidel, Hanka (Eschweiler); Seiler, Christoph Michael (Warendorf); Seltmann, Cornelia (Hachenburg); Senkal, Metin (Witten); Shamiyeh, Andreas (Linz); Shang, Edward (München); Siemssen, Björn (Berlin); Sievers, Dörte (Hamburg); Silbernik, Daniel (Bonn); Simon, Thomas (Sinsheim); Sinn, Daniel (Olpe); Sinning, Frank (Nürnberg); Smaxwil, Constatin Aurel (Stuttgart); Schabel, Volker (Kirchheim/Teck); Schadd, Peter (Euskirchen); Schassen von, Christian (Hamburg); Schattenhofer, Thomas (Vilshofen); Scheidbach, Hubert (Neustadt/Saale); Schelp, Lothar (Wuppertal); Scherf, Alexander (Pforzheim); Scheyer, Mathias (Bludenz); Schimmelpenning, Hendrik (Neustadt in Holstein); Schinkel, Svenja (Kempten); Schmid, Michael (Gera); Schmid, Thomas (Innsbruck); Schmidt, Rainer (Paderborn); Schmidt, Sven-Christian (Berlin); Schmidt, Ulf (Mechernich); Schmitz, Heiner (Jena); Schmitz, Ronald (Altenburg); Schöche, Jan (Borna); Schoenen, Detlef (Schwandorf); Schrittwieser, Rudolf/Bruck an der Mur); Schroll, Andreas (München); Schultz, Christian (BremenLesum); Schultz, Harald (Landstuhl); Schulze, Frank P. Mülheim an der Ruhr); Schumacher, Franz-Josef (Oberhausen); Schwab, Robert (Koblenz); Schwandner, Thilo
(Lich); Schwarz, Jochen Günter (Rottenburg); Schymatzek, Ulrich (Radevormwald); Spangenberger, Wolfgang (Bergisch-Gladbach); Sperling, Peter (Montabaur); Staade, Katja (Düsseldorf); Staib, Ludger (Esslingen); Stamm, Ingrid (Heppenheim); Stark, Wolfgang (Roth); Stechemesser, Bernd (Köln); Steinhilper, Uz (München); Stengl, Wolfgang (Nürnberg); Stern, Oliver (Hamburg); Stöltzing, Oliver (Meißen); Stolte, Thomas (Mannheim); Stopinski, Jürgen (Schwalmstadt); Stubbe, Hendrik (Güstrow/); Stülzebach, Carsten (Friedrichroda); Tepel, Jürgen (Osnabrück); Terzić, Alexander (Wildeshausen); Teske, Ulrich (Essen); Thews, Andreas (Schönebeck); Tichomirow, Alexej (Brühl); Tillenburg, Wolfgang (Marktheidenfeld); Timmermann, Wolfgang (Hagen); Tomov, Tsvetomir (Koblenz; Train, Stefan H. (Gronau); Trauzettel, Uwe (Plettenberg); Triechelt, Uwe (Langenhagen); Ulcar, Heimo (Schwarzach im Pongau); Unger, Solveig (Chemnitz); Verweel, Rainer (Hürth); Vogel, Ulrike (Berlin); Voigt, Rigo (Altenburg); Voit, Gerhard (Fürth); Volkers, Hans-Uwe (Norden); Vossough, Alexander (Neuss); Wallasch, Andreas (Menden); Wallner, Axel (Lüdinghausen); Warscher, Manfred (Lienz); Warwas, Markus (Bonn); Weber, Jörg (Köln); Weihrauch, Thomas (Ilmenau); Weiß, Johannes (Schwetzingen); Weißenbach, Peter (Neunkirchen); Werner, Uwe (Lübbecke-Rahden); Wessel, Ina (Duisburg); Weyhe, Dirk (Oldenburg); Wieber, Isabell (Köln); Wiesmann, Aloys (Rheine); Wiesner, Ingo (Halle); Withöft, Detlef (Neutraubling); Woehe, Fritz (Sanderhausen); Wolf, Claudio (Neuwied); Yaksan, Arif (Wermeskirchen); Yildirim, Selcuk (Berlin); Zarras, Konstantinos (Düsseldorf); Zeller, Johannes (Waldshut-Tiengen); Zhorzel, Sven (Agatharied); Zuz, Gerhard (Leipzig);

\section{References}

1. Bittner R, Leibl BJ, Jöger C, Kraft B, Ulrich M, Schwarz J (2006) TAPP-Stuttgart technique and result of a large single center series. J Minim Access Surg 2(3):155-159

2. Bittner R, Gmähle E, Gmühle B, Schwarz J, Aasvang E, Kehlet H (2010) Lightweight mesh and noninvasive fixation: an effective concept for prevention of chronic pain with laparoscopic hernia repair (TAPP). Surg Endosc 24(12):2958-2964. doi:10.1007/ s00464-010-1140.9

3. Fortelny RH, Petter-Puchner AH, May C, Jaksch W, Benesch T, Khakpour Z, Redl H, Glaser KS (2012) The impact of atraumatic fibrin sealant vs. staple mesh fixation in TAPP hernia repair on chronic pain and quality of life: results of a randomized controlled study. Surg Endosc 26(1):249-254. doi:10.1007/s00464011-1862-3

4. Lau H (2005) Fibrin sealant versus mechanical stapling for mesh fixation during endoscopic extraperitoneal inguinal hernioplasty: a randomized prospective trial. Ann Surg 242:670-675

5. Olmi S, Scaini A, Erba L, Guaglio M, Groce E (2007) Quantification of pain in laparoscopic transabdominal preperitoneal 
(TAPP) inguinal hernioplasty identifies marked differences between prothesis fixation systems. Surgery 142:40-46

6. Lovisetto F, Zonta S, Rota E, Mazzilli M, Bardone M, Bottero L, Faillace G, Longoni M (2007) Use of human fibrin glue (Tissucol) versus staples for mesh fixation in laparoscopic transabdominal preperitoneal hernioplasty: a prospective, randomized study. Ann Surg 245:222-231

7. Tam KW, Liang Hung-Hua, Chai Chiah-Yang (2010) Outcomes of staple fixation of mesh versus nonfixation in laparoscopic total extraperitoneal inguinal repair: a meta-analysis of randomized controlled trials. World J Surg 34(12):3065-3074. doi:10.1007/ s00268-010-0760-5

8. Koch CA, Greenlee SM, Larson DR, Harrington JR, Farley DR (2006) Randomized prospective study of totally extraperitoneal inguinal hernia repair: fixation versus no fixation of mesh. JSLS 10:457-460

9. Bittner R, Arregui ME, Bisgaard T, Dudai M, Ferzli GS, Fitzgibbons RJ, Fortelny RH, Klinge U, Kockerling F, Kuhry E, Kukleta J, Lomanto D, Misra MC, Montgomery A, MoralesConde S, Reinpold W, Rosenberg J, Sauerland S, Schug-Paß C, Singh K, Timoney M, Weyhe D, Chowbey P (2011) Guidelines for laparoscopic (TAPP) and endoscopic (TEP) treatment of inguinal hernia [International Endohernia Society (IEHS)]. Surg Endosc 25:2773-2843. doi:10.1007/s00464-011-1799-6

10. Bittner R, Montgomery MA, Arregui E, Bansal V, Bingener J, Bisgaard T, Buhck H, Dudai M, Ferzli GS, Fitzgibbons RJ, Fortelny RH, Grimes KL, Klinge U, Koeckerling F, Kumar S, Kukleta J, Lomanto D, Misra MC, Morales-Conde S, Reinpold W, Rosenberg J, Singh K, Timoney M, Weyhe D, Chowbey P (2015) Update of guidelines on laparoscopic (TAPP) and endoscopic (TEP) treatment of inguinal hernia (International Endohernia Society). Surg Endosc 29:289-321. doi:10.1007/s00464014-3917-8

11. Stechemesser B, Jacob DA, Schug-Paß C, Köckerling F (2012) Herniamed: an internet-based registry for outcome research in hernia surgery. Hernia 16(3):269-276. doi:10.1007/s10029-0120908.3
12. Miserez M, Alexandre JH, Campanelli G, Corcione F, Cuccurullo D, Pascual MH, Hoeferlin A, Kongsnorth AN, Mandala V, Palot JP, Schumpelick V, Simmermacher RK, Stoppa R, Flament JB (2007) The European hernia society groin hernia classification: simple and easy to remember. Hernia 11(2):113-116

13. Smith AI, Royston CM, Sedman PC (1999) Stapled and nonstapled laparoscopic transabdominal preperitoneal (TAPP) inguinal hernia repair: a prospective randomized trial. Surg Endosc 13:804-806

14. Burcharth J, Pommergaard HC, Bisgaard T, Rosenberg J (2015) Patient-related risk factors for recurrence after inguinal hernia repair: a systematic review and meta-analysis of observational studies. Surg Innov 22(3):303-317. doi:10.1177/ 1553350614552731

15. Lau H, Lee F (2003) Seroma following endoscopic extraperitoneal inguinal hernioplasty. Surg Endosc 17:1773-1777. doi:10. 1007/s00464-002-8771-4

16. Reddy VM, Sutton CD, Bloxham L, Garcea G, Ubhi SS, Robertson GS (2007) Laparoscopic repair of direct inguinal hernia: a new technique that reduces the development of postoperative seroma. Hernia 11:393-396. doi:10.1007/s10029-0070233-4

17. Choi YY, Kim Z, Hur KY (2011) Sewlling after laparoscopic total extraperitoneal repair of inguinal hernias: review of one surgeon's experience in 1,065 cases. World J Surg 35:43-46. doi:10.1007/s00268-010-0843-3

18. Berney CR (2012) The Endoloop technique for the primary closure of direct inguinal hernia defect during the endoscopic totally extraperitoneal approach. Hernia 16:301-305. doi:10. 1007/s10029-011-0892-z

19. Köckerling F, Jacob DA, Lomanto D, Chowbey P (2012) C. R. Berny: "The Endoloop technique for the primary closure of direct inguinal hernia defect during the endoscopic totally extraperitoneal approach". Hernia 16:493-494. doi:10.1007/ s10029-012-0920-7 